\title{
Expression of Toll-like receptors on peritoneal macrophages and dendritic cells from old mice treated with soyabean isoflavones and green tea
}

\author{
I. Baeza, N. M. de Castro, L. Arranz and M. de la Fuente \\ Complutense University of Madrid, Faculty of Biology, Department of Physiology, Madrid, Spain
}

Cells of the immune system recognize pathogens via Toll-like receptors (TLR), which are the basic signalling receptors of the innate immune system and direct the course of acquired immunity by recognizing specific microbial products that activate immune cells for effector functions ${ }^{(1)}$. It is well known that ageing correlates with a decline in immunity, an increase in the inflammatory state and an impaired production of several hormones, such as oestrogens ${ }^{(2)}$. In recent years it has been shown that oestrogens play an essential role in modulating immune function and pro-inflammatory cell signalling ${ }^{(2,3)}$. Soyabean isoflavones, since they show a structural similarity to oestradiol, are being investigated in order to determine whether they can mimic oestrogen actions ${ }^{(4)}$. Furthermore, the possible effects of the green tea plant on human health, because of its content of polyphenolic antioxidants (especially catechins), has been studied with increasing interest in recent years ${ }^{(5)}$. Since the expression of TLR on cell membranes constitutes the first step in the inflammatory signalling cascade, the aim of the present study was to determine the role of isoflavones and green tea as modulators of such TLR expression on peritoneal macrophages and dendritic cells (those that mediate innate immunity) from old mice.

ICR-CD1 female mice aged 16 months were fed a diet supplemented with soyabean or green tea + soyabean (Diviser-Aquilea SL, Barcelona, Spain; $1 \mathrm{mg}$ soyabean per mouse per d; $3.75 \mathrm{mg}$ green tea per mouse per d) for 25 weeks. The control groups were fed standard diet (A04; Panlab LS, Barcelona, Spain). Then, at the age of 22 months peritoneal leucocytes were obtained from the animals and the expression of TLR 2 and 4 was determined by flow cytometry in macrophages and dendritic cells.

Previous studies have detected an increased expression of TLR2 and TLR4 with advancing age (L. Arranz, I. Baeza, N. M. De Castro, and M. De la Fuente, unpublished results). In the present experiment the combined diet (soyabean isoflavones + green tea) significantly decreased the presence of TLR2 and TLR4 on cell membranes in the old animals. In conclusion, adequate treatment with isoflavones and green tea could be useful in slowing down the effects of the ageing process through a mechanism of control of the age-related inflammatory state.
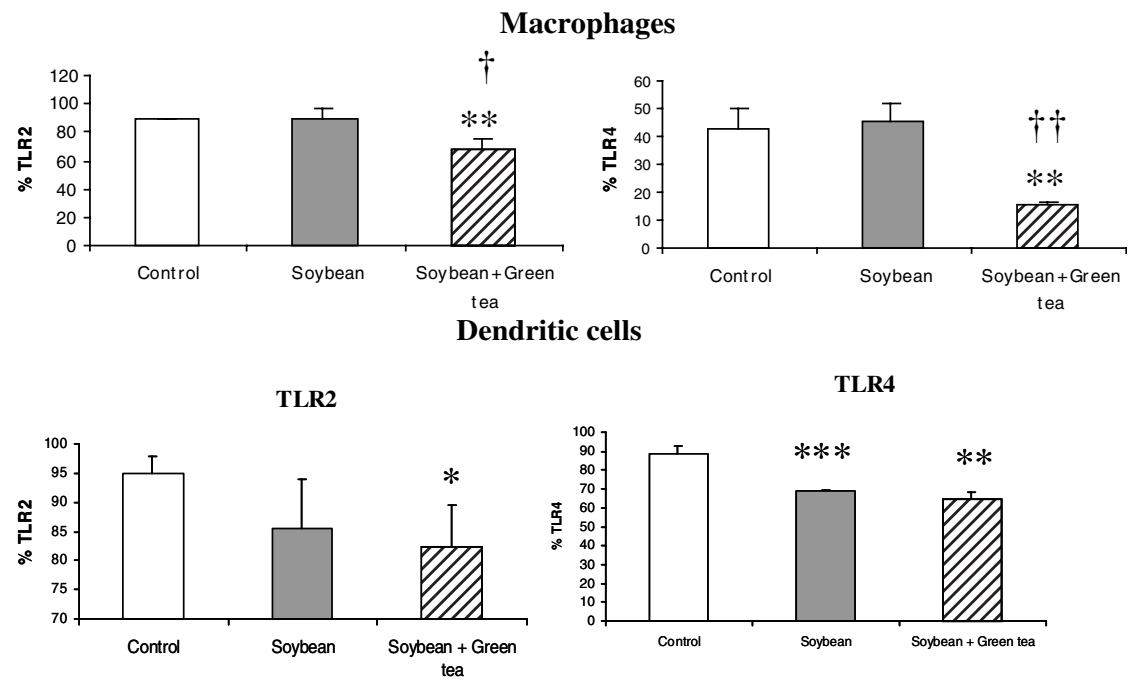

Figure. Expression of TLR2 and TLR4 on macrophages and dendritic peritoneal cells. Values are means and standard deviations represented by vertical bars for groups of four animals. Mean values were significantly different from those for control animals: $* P<0.05, * * P<0.01, * * * P<0.001$. Mean values were significantly different from those for the soyabean group: $† P<0.05, \dagger \dagger P<0.01$.

This work has been supported by Uriach-Aquilea OTC SL, the MEC (BFU 2005-06777) and RETICEF (RD06/0013/0003) (ISCIII) of Spain.

1. Mukhopadhyay S, Herre J, Brown GD \& Gordon S (2004) Immunology 112, 521-530.

2. Rehman HU \& Masson EA (2005) Gend Med 2, 41-56.

3. Lesmeister MJ, Jorgenson LR, Young SL \& Misfeldt ML (2005) Reprod Biol Endocrinol 3, 74.

4. Gris Martínez JM (2006) Med Clin (Barc) 127, 352-356.

5. Friedman M (2007) Mol Nutr Food Res 51, 116-134. 